International Journal of Biology, Pharmacy and Allied Seiences (IJBPAS) 'A Bridge Betuen Caboratory and Qnendo' Www.ijbpas.com

\title{
CHRONIC FATIGUE SYNDROME - AN UPDATE
}

\section{NEHA $\mathbf{N}^{1}$, ANITHA ROY ${ }^{2^{*}}$ AND JAYALAKSHMI SOMASUNDARAM ${ }^{3}$}

1: Research Associate, Saveetha Dental College and Hospitals, Saveetha Institute of Medical and Technical Sciences, Saveetha University, Chennai- 600077, Tamil Nadu, India

2: Associate Professor, Department of Pharmacology, Saveetha Dental College and Hospitals, Saveetha Institute of Medical and Technical Sciences, Saveetha University, Chennai- 600077, Tamil Nadu, India

3: Chief Scientist, White Lab- Material Research Centre, Saveetha Dental College and Hospitals, Saveetha Institute of Medical and Technical Sciences, Saveetha University, Chennai- 600077, Tamil Nadu, India

*Corresponding Author: E Mail: Dr. Anitha Roy: anitharoy@saveetha.com

Received 19 ${ }^{\text {th }}$ March 2021; Revised 20 ${ }^{\text {th }}$ April. 2021; Accepted $19^{\text {th }}$ May 2021; Available online $1^{\text {st }}$ Aug. 2021 https://doi.org/10.31032/IJBPAS/2021/10.8.1016

ABSTRACT

Chronic fatigue syndrome or myalgic encephalomyelitis is a disorder characterised by disruptive and persistent fatigue, sleep abnormalities, pain and long- term illness, affecting the quality of life. The mechanism underlying the condition is not completely understood. The mechanisms are multiple and complex with no single causative mechanism identified. The condition is associated with a myriad of symptoms, the main symptom is fatigue persisting for over six months or sometimes prolonging for years. The fatigue usually worsens with activity but does not resolve with rest. It is found to have comorbidity with a number of conditions which include Hashimoto's thyroiditis, Postural orthostatic tachycardia syndrome, presence of autoimmune diseases in family history, etc. The basic need is to be fit, healthy and energetic in day to day life. CFS has caused a reduction in the quality of life and has a major impact on the social and economic status of an individual leading to the inability to lead a normal life, productivity losses 
and health care expenses. It accounts for more than 1 million cases per year in India. It is found to be more prevalent among women which are attributed to impairment in estrogen and estrogen receptors. Treatment can help, but this condition cannot be cured. Stress management, relaxation techniques and appropriate medications designated to relieve the symptoms are recommended.

Keywords: Chronic fatigue syndrome; myalgic encephalomyelitis; long-term illness; pain; fatigue; headache; physical inactivity

\section{INTRODUCTION}

Chronic fatigue syndrome, also known as myalgic encephalomyelitis or chronic fatigue immune dysfunction syndrome or post-viral fatigue syndrome [1] or Paediatric chronic fatigue syndrome (in children) [2] is a condition of frequent and persistent chronic generalised fatigue severely affecting the quality of life. The term was coined by Holmes in 1988 [3]. The term 'myalgic encephalomyelitis (ME)' is often used, but 'CFS' is the term that has been adopted and clearly defined for research purposes [4]. Chronic fatigue syndrome (CFS) is a serious disorder characterised by poor stamina, persistent post-exertional fatigue (which may be physical or mental fatigue) and symptoms related to cognitive, immune and autonomic dysfunction [5]. It is a multisystem illness that robs its victims of their health and their dignity [6].

CFS is associated with a myriad of symptoms but the core symptom associated with the disease is unexplained disabling fatigue persisting over 6 months or sometimes for

years $[7,8]$ In addition to this, headaches, fatigue [9], loss of memory, difficulty in concentration [10], sleep abnormalities and unrefreshing sleep [11], anxiety, depression [12], cognitive dysfunction, fibromyalgia [13], pain in muscles and joints [14], enlarged and painful lymph nodes in the neck or armpits [15], sore throat, inability to perform normal activities, deterioration after physical activity [16] and severe exhaustion which may even confine the patients to bed [17]. Thus, CFS presents itself as a common, debilitating and serious health problem.

Despite several attempts worldwide, no single aetiology has been reported to elucidate the onset of this syndrome. It is believed that a variety of causes induce the development of CFS. Thus, the underlying mechanism and aetiology of Chronic fatigue syndrome are not well established [4]. However, immunological (e.g. presence of infections, the role of autoantibodies, natural killer cells, immune-inflammatory and O \& NS pathways), metabolic (mitochondrial 
dysfunction, activation of certain enzymes, acidosis and metabolomics), neurological (cognitive abnormalities, the role of glial cells, circadian regulators and disturbances in sleep), neuroendocrine (HPA axis hypoactivity) and psychological aspects (melancholic depression, bipolar disorder, etc) play a significant role.

\section{IMMUNOLOGICAL ASPECTS:}

The onset of CFS is often reported to be triggered by the presence of infections, most commonly viral infections because some people develop CFS after suffering through viral infections. Suspicious viruses include Epstein-Barr virus, human herpesvirus 6 and mouse leukaemia viruses [18]. The role of autoimmune mechanisms, abnormal immune response elucidated by the presence of autoantibodies and immune dysfunction in Chronic Fatigue Syndrome is a multi-sided hallmark that requires further attention [19]. Alterations in cytokine profile and decreased function of NK cells produce flu-like symptoms [20]. Alterations in the immuneinflammatory pathway and Oxidative and Nitrosative (O\& NS) pathways [7] also play a significant role in CFS.

\section{METABOLIC ASPECTS:}

Several metabolic aspects have also been found to play an important role in CFS. The important attributes are mitochondrial dysfunction, impairment in 5-AMPK and metabolomics.

\section{Mitochondrial dysfunction:}

Fatigue is due to lack of energy and energy is obtained by oxidation of food. The mitochondria are the powerhouse of the cell. It has an important role in almost every cell of the body. Thus mitochondrial dysfunction is also assumed to be the immediate cause of CFS symptoms [6].

\section{5'-Adenosine monophosphate-activated protein kinase:}

AMPK is an enzyme that plays an important role in maintaining metabolic homeostasis within a cell. It is a central component of cellular metabolism and plays an important role in regulating growth and metabolism. Thus impairment of 5-AMPK is also presumed to contribute to the pathogenesis of CFS [21].

\section{Skeletal muscle acidosis:}

Previous studies have observed overdepletion of energy stores in the skeletal muscles of CFS patients. It has been suggested that this is attributed to overutilization of the anaerobic respiratory pathways in the cells which leads to decreased capacity of the patient to exercise [22]. 


\section{Metabolomics:}

Few authors suggest that patients suffering from CFS have a homogenous metabolic response and plasma metabolomics could be used as a biomarker for CFS/ME. This concept is not conclusive. Additionally, patients suffering from diseases with fatigue as a core symptom, such as fibromyalgia, Primary Sjogren's syndrome, and type 2 diabetes, should be assessed to see if the metabolic response identified here is unique to CFS/ME. Thus, further work is needed to provide conclusive results [23].

\section{NEUROENDOCRINE ASPECTS:}

CFS is associated with neuroendocrine disturbances, cognitive impairment [24] role of glial cells, circadian regulators and HPA axis dysfunction or hypoactivity which is a multifactorial heterogeneous aetiology leading to inactivity and sleep disturbances [25].

\section{PSYCHOLOGICAL ASPECTS:}

Melancholic depression, bipolar disorder or psychosis-depression and other mechanisms lead to symptoms of CFS which include anxiety, depression, emotional and behavioural changes affecting the psychology of the patient [12].

\section{SOCIO-ECONOMIC IMPACT:}

The basic need is to be fit, healthy and energetic in day to day life. CFS has a major impact on the social and economic status of an individual leading to the inability to lead a normal life and reduced quality of life than for other chronic illness groups [26]. Because of the functional disability associated with CFS, there are productivity losses, health care expenses and marked interruption of work and family and social life of the affected subjects [11].

\section{COMORBIDITY:}

Comorbidity is the presence of one or more additional conditions co-occurring with a primary condition. CFS is found to have a wide range of additional conditions cooccurring with [27] which includes Hashimoto's thyroiditis, Postural orthostatic tachycardia syndrome, presence of autoimmune diseases in family history, etc. Hashimoto's thyroiditis is seen in about 17$20 \%$ of ME/CFS patients [28]. About 11$40 \%$ of ME/CFS patients suffer from POTS (Postural orthostatic tachycardia syndrome) [29]. A substantial number of ME/CFS patients have a family history of autoimmune diseases [30]. Chronic fatigue is a core symptom of fibromyalgia, hypothyroidism, endometriosis [31], type-2 diabetes [32], cancers like colon cancer [33], lung cancer [34], oral squamous cell carcinoma [35], irritable bowel syndrome, etc. [20]. 


\section{PREVALENCE OF CFS:}

The prevalence of Chronic fatigue syndrome relies on self-reporting of the condition or symptoms to a general physician [9]. There is a high heterogeneity present regarding the prevalence of the condition (6). Prevalence is biased by differential access to health care treatment. The factors playing a role are age, sex, ethnic identification, socio-economic status, etc. [36]. About 2.5 million individuals are affected by CFS in the US (17). The CDC estimates that more than 1 million cases per year are found in India and the US. About 17-24 million people worldwide are affected by the condition. The age group associated prevalence of the condition differs. It is rare in children (6-13 yrs), common among Teenagers (14-18 yrs), adults (41-60 yrs) and seniors (60+ yrs) and very common among young adults (1940yrs) [37].

\section{PREVALENCE AMONG WOMEN:}

It has been observed that CFS has a higher frequency and impact on female subjects than male subjects [38]. The possible reason is yet to be elucidated, but it is suggested that estrogen and estrogen receptors, particularly the ER-beta receptors are impaired and lowly expressed in female patients of CFS [39]. Women with endometriosis more often suffer from autoimmune inflammatory diseases, fibromyalgia, chronic fatigue syndrome, hypothyroidism, allergies and asthma [31].

\section{DIAGNOSIS:}

Self-reporting of the condition or symptoms to a general physician is necessary. The diagnosis stating the condition as CFS is given only in disease states with a minimum history of about 6 months and is identified only after all the other etiologies which might cause fatigue have been ruled out. Nonspecific laboratory tests and blood tests are suggested. There is no proper diagnostic protocol for the condition $[\mathbf{4 0 , 4 1 ]}$.

\section{TREATMENT:}

The primary treatment for Chronic fatigue syndrome is stress management, relaxation techniques and antidepressant medications. Recently a number of clinical studies have been conducted to test the effectiveness of other treatment approaches like nutritional therapy, exercise therapy, cognitive behavioural therapy etc.

\section{NUTRITIONAL THERAPY:}

Numerous articles have reported that some nutritional deficiencies could be involved in the aetiology of CFS. These include deficiencies of vitamins including vitamin $C$, vitamin B complex, minerals like sodium, magnesium, zinc, folic acid, and other products like essential fatty acids, and coenzymes [42]. There is still only a little 
data to provide a promising hypothesis for the effective role of supplementation of appropriate minerals, vitamins, plant nutrients [43] in the CFS pathophysiology and therapy. Thus further examination has to be done to achieve more awareness in the efficacy of minerals and vitamins in the CFS pathophysiology [20].

PLANT MEDIATED RESEARCH IN THE MANAGEMENT OF DISEASES:

Several plant-mediated researches have been conducted in the last 2 decades to evaluate the efficacy of plant extracts [44] and plant products [45] in the management of diseases such as hepatic fibrosis, diabetes mellitus, atherosclerosis, etc [46]. Constituents of natural fruits and vegetables like syringic acid have also shown significant results in the treatment of hepatotoxicity [47]. Oxidative stress has an important role in the pathogenesis of various chronic disorders and several plant-derived antioxidant principles have been employed against oxidative stress and have shown effective and promising results in humans [48]. Nanoparticles synthesized from plant and plant extracts which include silver [49] zinc oxide [50, 51], and selenium nanoparticles [52] have shown hepatoprotective, anti-inflammatory, chemotherapeutic, immunomodulatory, cytotoxic, antimicrobial, antibacterial, free radical scavenging, and antioxidant activities. Recently, oligonucleotide-based therapies have been employed in the treatment of chronic diseases [53].

\section{MEDICATIONS- ANTIDEPRESSANT THERAPY:}

Young people with CFS/ME are disabled. About $30 \%$ of individuals are affected with comorbid anxiety and depression [54]. Although not everyone with chronic fatigue syndrome is depressed, some antidepressants can help ease fatigue, pain and disordered sleep [40].

\section{EXERCISE THERAPY}

Exercise therapy is an umbrella term for the different types of exercise provided, some of which include graded exercise therapy (GET): an exercise in which the incremental increase in exercise was mutually set; exercise with pacing: an exercise in which the incremental increase in exercise was personally set; anaerobic exercise: exercise that requires a high level of exertion, in a brief spurt or short-term in duration by the participant that can be gradually increased over time with practice [4]. Moderate-quality evidence showed exercise therapy was more effective at reducing fatigue compared to 'passive' treatment or no treatment but had similar or lesser effectiveness than CBT [2]. It had a positive effect on people's daily 
physical functioning, sleep and self-ratings of overall health but information makes it difficult to bring proper conclusions about the safety of exercise therapy.

\section{COGNITIVE}

BEHAVIOURAL

\section{THERAPY:}

CBT is believed to be effective in reducing the symptoms of fatigue at post-treatment and may be more effective in reducing fatigue symptoms compared to other psychological therapies. But there is a lack of evidence on the comparative effectiveness of CBT alone in the treatment of CFS and CBT in combination with other treatments. Thus, further studies are required to arrive at a proper conclusion [55]. However, NICE (The National Institute for Health and Clinical Excellence) recommends that young people with CFS/ME can be offered either Cognitive Behavioural Therapy $[\mathbf{5 6}, 57]$ (CBT, which focuses on strategies to identify, challenge and change fatigue-related cognitive processes and gradually resume activities), Graded Exercise Therapy (GET) or Activity Management (a goal-oriented and personcentred approach which establishes a baseline for all activity, which is then increased) [58, 59] $\mathrm{CBT}$ and GET are moderately effective in adults with CFS/ME (4) [60].

\section{CONCLUSION}

Chronic fatigue syndrome/ Myalgic encephalomyelitis is a condition of profound and prolonged illness, characterised by the core symptom of unexplained fatigue for months or years. The principal pathological/etiological mechanism causing the condition is unknown and shows the role of myriad aspects in the disease. There is no standard diagnosis and treatment protocol for the disease, which puts forward the need for further research for a better understanding of the condition and providing the best treatment care to the patients.

\section{REFERENCES}

[1] Anderson E, Gaunt D, Metcalfe C, Rai M, Hollingworth W, Mills N, et $a l$. Investigating the effectiveness and cost-effectiveness of FITNET-NHS (Fatigue In Teenagers on the interNET in the NHS) compared to activity management to treat paediatric chronic fatigue syndrome (CFS)/myalgic encephalomyelitis (ME): amendment to the published protocol [Internet]. Vol. 20, Trials. 2019. Available from: http://dx.doi.org/10.1186/s13063019-3895-1

[2] Baos S, Brigden A, Anderson E, Hollingworth W, Price S, Mills N, et 
al. Investigating the effectiveness and cost-effectiveness of FITNET-NHS (Fatigue In Teenagers on the interNET in the NHS) compared to Activity Management to treat paediatric chronic fatigue syndrome (CFS)/myalgic encephalomyelitis (ME): protocol for a randomised controlled trial [Internet]. Vol. 19, Trials. 2018. Available from: http://dx.doi.org/10.1186/s13063-

018-2500-3

[3] Holmes GP. Chronic Fatigue Syndrome: A Working Case Definition [Internet]. Vol. 108, Annals of Internal Medicine. 1988. p. 387. Available from: http://dx.doi.org/10.7326/0003-4819108-3-387

[4] Larun L, Brurberg KG, OdgaardJensen J, Price JR. Exercise therapy for chronic fatigue syndrome. Cochrane Database Syst Rev. 2016 Dec 20;12:CD003200.

[5] Brurberg KG, Fønhus MS, Larun L, Flottorp S, Malterud K. Case definitions for chronic fatigue syndrome/myalgic encephalomyelitis (CFS/ME): a systematic review. BMJ Open. 2014 Feb 7;4(2):e003973.

[6] Myhill S, Booth NE, McLaren-
Howard J. Chronic fatigue syndrome and mitochondrial dysfunction. Int $\mathrm{J}$ Clin Exp Med. 2009 Jan 15;2(1):116.

[7] Morris G, Anderson G, Maes M. Hypothalamic-Pituitary-Adrenal Hypofunction in Myalgic Encephalomyelitis (ME)/Chronic Fatigue Syndrome (CFS) as a Consequence of Activated ImmuneInflammatory and Oxidative and Nitrosative Pathways [Internet]. Vol. 54, Molecular Neurobiology. 2017. p. 6806-19. Available from: http://dx.doi.org/10.1007/s12035016-0170-2

[8] Morris G, Stubbs B, Köhler CA, Walder K, Slyepchenko A, Berk M, et al. The putative role of oxidative stress and inflammation in the pathophysiology of sleep dysfunction across neuropsychiatric disorders: Focus on chronic fatigue syndrome, bipolar disorder and multiple sclerosis [Internet]. Vol. 41, Sleep Medicine Reviews. 2018. p. 255-65. Available from: http://dx.doi.org/10.1016/j.smrv.2018 .03 .007

[9] Johnston S, Brenu EW, Staines D, Marshall-Gradisnik S. The prevalence 
of chronic fatigue syndrome/ myalgic encephalomyelitis: a meta-analysis.

Clin Epidemiol. 2013 Mar 26;5:10510.

[10] Newberry F, Hsieh S-Y, Wileman $\mathrm{T}$, Carding SR. Does the microbiome and virome contribute to myalgic encephalomyelitis/chronic fatigue syndrome? [Internet]. Vol. 132, Clinical Science. 2018. p. 523-42. Available from: http://dx.doi.org/10.1042/cs2017133 0

[11] Reynolds KJ, Vernon SD, Bouchery E, Reeves WC. Cost Effectiveness and Resource Allocation [Internet]. Vol. 2. 2004. p. 4. Available from: http://dx.doi.org/10.1186/14787547-2-4

[12] Rao AV, Venket Rao A, Bested AC, Beaulne TM, Katzman MA, Iorio C, et al. A randomized, double-blind, placebo-controlled pilot study of a probiotic in emotional symptoms of chronic fatigue syndrome [Internet]. Vol. 1, Gut Pathogens. 2009. p. 6. Available from: http://dx.doi.org/10.1186/17574749-1-6

[13] Teodoro T, Edwards MJ, Isaacs JD.
A unifying theory for cognitive abnormalities in functional neurological disorders, fibromyalgia and chronic fatigue syndrome: systematic review [Internet]. Vol. 89, Journal of Neurology, Neurosurgery \& Psychiatry. 2018. p. 1308-19. Available from: http://dx.doi.org/10.1136/jnnp-2017317823

[14] Lacourt TE, Vichaya EG, Chiu GS, Dantzer R, Heijnen CJ. The High Costs of Low-Grade Inflammation: Persistent Fatigue as a Consequence of Reduced Cellular-Energy Availability and Non-adaptive Energy Expenditure [Internet]. Vol. 12, Frontiers in Behavioral Neuroscience. 2018. Available from:

http://dx.doi.org/10.3389/fnbeh.201 8.00078

[15] Tomas C, Newton J. Metabolic abnormalities in chronic fatigue syndrome/myalgic encephalomyelitis: a mini-review [Internet]. Vol. 46, Biochemical Society Transactions. 2018. p. 54753. Available from: http://dx.doi.org/10.1042/bst201705 03 
[16] Becker PD, De Becker P, Roeykens J, Reynders M, McGregor N, De Meirleir K. Exercise Capacity in Chronic Fatigue Syndrome [Internet]. Vol. 160, Archives of Internal Medicine. 2000. p. 3270. Available from: http://dx.doi.org/10.1001/archinte.1 60.21 .3270

[17] Clayton EW. Beyond Myalgic Encephalomyelitis/Chronic Fatigue Syndrome [Internet]. Vol. 313, JAMA. 2015. p. 1101. Available from:

http://dx.doi.org/10.1001/jama.2015. 1346

[18] Ascherio A, Munger KL. EBV and Autoimmunity [Internet]. Current Topics in Microbiology and Immunology. 2015. p. 365-85. Available from:

http://dx.doi.org/10.1007/978-3319-22822-8_15

[19] Sotzny F, Blanco J, Capelli E, Castro-Marrero J, Steiner S, Murovska $\mathrm{M}$, et al. Myalgic Encephalomyelitis/Chronic Fatigue Syndrome - Evidence for an autoimmune disease [Internet]. Vol. 17, Autoimmunity Reviews. 2018. p. 601-9. Available from: http://dx.doi.org/10.1016/j.autrev.20 18.01.009

[20] Bjørklund G, Dadar M, Pen JJ, Chirumbolo S, Aaseth J. Chronic fatigue syndrome (CFS): Suggestions for a nutritional treatment in the therapeutic approach [Internet]. Vol. 109, Biomedicine \& Pharmacotherapy. 2019. p. 1000-7. Available from: http://dx.doi.org/10.1016/j.biopha.2 018.10 .076

[21] Mihaylova MM, Shaw RJ. The AMPK signalling pathway coordinates cell growth, autophagy and metabolism [Internet]. Vol. 13, Nature Cell Biology. 2011. p. 101623. Available from: http://dx.doi.org/10.1038/ncb2329

[22] Jones DEJ, Hollingsworth KG, Taylor R, Blamire AM, Newton JL. Abnormalities in $\mathrm{pH}$ handling by peripheral muscle and potential regulation by the autonomic nervous system in chronic fatigue syndrome [Internet]. Vol. 267, Journal of Internal Medicine. 2010. p. 394401. Available from: http://dx.doi.org/10.1111/j.13652796.2009.02160.x

[23] Naviaux RK, Naviaux JC, Li K, 
Taylor Bright A, Alaynick WA, Wang L, et al. Metabolic features of chronic fatigue syndrome [Internet]. Vol. 113, Proceedings of the National Academy of Sciences. 2016. p. E5472-80. Available from: http://dx.doi.org/10.1073/pnas.1607 571113

[24] Lorusso L, Mikhaylova SV, Capelli E, Ferrari D, Ngonga GK, Ricevuti G. Immunological aspects of chronic fatigue syndrome. Autoimmun $\quad$ Rev. 2009 Feb;8(4):287-91.

[25] Cleare AJ. The Neuroendocrinology of Chronic Fatigue Syndrome [Internet]. Vol. 24, Endocrine Reviews. 2003. p. 236-52. Available from:

http://dx.doi.org/10.1210/er.20020014

[26] Jason LA, Jordan K, Miike T, Bell DS, Lapp C, Torres-Harding S, et al. A Pediatric Case Definition for Myalgic Encephalomyelitis and Chronic Fatigue Syndrome [Internet]. Vol. 13, Journal of Chronic Fatigue Syndrome. 2006. p. 1-44. Available from: http://dx.doi.org/10.1300/j092v13n0 2_01
[27] Castro-Marrero J, Faro M, Aliste L, Sáez-Francàs N, Calvo N, MartínezMartínez A, et al. Comorbidity in Chronic Fatigue Syndrome/Myalgic Encephalomyelitis: A Nationwide Population-Based Cohort Study [Internet]. Vol. 58, Psychosomatics. 2017. p. 533-43. Available from: http://dx.doi.org/10.1016/j.psym.201 7.04 .010

[28] Loebel M, Grabowski P, Heidecke H, Bauer S, Hanitsch LG, Wittke K, et al. Antibodies to $\beta$ adrenergic and muscarinic cholinergic receptors in patients with Chronic Fatigue Syndrome [Internet]. Vol. 52, Brain, Behavior, and Immunity. 2016. p. 32-9. Available from: http://dx.doi.org/10.1016/j.bbi.2015. 09.013

[29] Dahan S, Tomljenovic L, Shoenfeld Y. Postural Orthostatic Tachycardia Syndrome (POTS) - A novel member of the autoimmune family [Internet]. Vol. 25, Lupus. 2016. p. 339-42. Available from: http://dx.doi.org/10.1177/09612033 16629558

[30] Fluge Ø, Risa K, Lunde S, Alme K, Rekeland IG, Sapkota D, et al. BLymphocyte Depletion in Myalgic 
Encephalopathy/ Chronic Fatigue

Syndrome. An Open-Label Phase II

Study with Rituximab Maintenance

Treatment. PLoS One. 2015 Jul 1;10(7):e0129898.

[31] Sinaii N, Cleary SD, Ballweg ML, Nieman LK, Stratton P. High rates of autoimmune and endocrine disorders, fibromyalgia, chronic fatigue syndrome and atopic diseases among women with endometriosis: a survey analysis. Hum Reprod. 2002 Oct;17(10):2715-24.

[32] Anitha R, Ashwini S. Antihyperglycemic activity of Caralluma fimbriata: An In vitro approach [Internet]. Vol. 13, Pharmacognosy Magazine. 2017. p. 499. Available from: http://dx.doi.org/10.4103/pm.pm_59 $-17$

[33] Ashwini S, Ezhilarasan D, Anitha R. Cytotoxic Effect of Caralluma fimbriata Against Human Colon Cancer Cells [Internet]. Vol. 9, Pharmacognosy Journal. 2017. p. 204-7. Available from: http://dx.doi.org/10.5530/pj.2017.2. 34

[34] Sharma P, Mehta M, Dhanjal DS,
Kaur S, Gupta G, Singh H, et al. Emerging trends in the novel drug delivery approaches for the treatment of lung cancer [Internet]. Vol. 309, Chemico-Biological Interactions. 2019. p. 108720. Available from: http://dx.doi.org/10.1016/j.cbi.2019. 06.033

[35] Lakshmi T, Ezhilarasan D, Vijayaragavan R, Bhullar SK, Rajendran R. ethanolic bark extract induces apoptosis in human oral squamous carcinoma cells. J Adv Pharm Technol Res. 2017 Oct;8(4):143-9.

[36] Scartozzi S, Sunnquist M, Jason LA. Myalgic encephalomyelitis and chronic fatigue syndrome case definitions: effects of requiring a substantial reduction in functioning. Fatigue. 2019 Apr 1;7(2):59-68.

[37] Jason LA, Richman JA, Rademaker AW, Jordan KM, Plioplys AV, Taylor RR, et al. A communitybased study of chronic fatigue syndrome. Arch Intern Med. 1999 Oct 11;159(18):2129-37.

[38] Faro M, Sàez-Francás N, CastroMarrero J, Aliste L, de Sevilla TF, Alegre J. Gender Differences in 
Chronic Fatigue Syndrome

[Internet]. Vol. 12, Reumatología

Clínica (English Edition). 2016. p.

72-7. Available from:

http://dx.doi.org/10.1016/j.reumae.2

015.05 .009

[39] Grans H, Nilsson M, DahlmanWright K, Evengard B. Reduced levels of oestrogen receptor mRNA in Swedish patients with chronic fatigue syndrome [Internet]. Vol. 60, Journal of Clinical Pathology. 2006. p. 195-8. Available from: http://dx.doi.org/10.1136/jcp.2005.0 35956

[40] Carruthers BM, Jain AK, De Meirleir KL, Peterson DL, Klimas NG, Martin Lerner A, et al. Myalgic Encephalomyelitis/Chronic Fatigue Syndrome [Internet]. Vol. 11, Journal of Chronic Fatigue Syndrome. 2003. p. 7-115. Available from: http://dx.doi.org/10.1300/j092v11n0 1_02

[41] Carruthers BM, van de Sande MI, De Meirleir KL, Klimas NG, Broderick G, Mitchell $\mathrm{T}$, et al. Myalgic encephalomyelitis: International Consensus Criteria [Internet]. Vol. 270, Journal of
Internal Medicine. 2011. p. 327-38. Available from: http://dx.doi.org/10.1111/j.13652796.2011.02428.x

[42] Regland B, Forsmark S, Halaouate L, Matousek M, Peilot B, Zachrisson $\mathrm{O}$, et al. Response to vitamin B12 and folic acid in myalgic encephalomyelitis and fibromyalgia. PLoS One. 2015 Apr 22;10(4):e0124648.

[43] Lakshmi T, Krishnan V, Rajendran R, Madhusudhanan N. Azadirachta indica : A herbal panacea in dentistry - An update [Internet]. Vol. 9, Pharmacognosy Reviews. 2015. p. 41. Available from: http://dx.doi.org/10.4103/09737847.156337

[44] Ezhilarasan D, Lakshmi T, Nagaich U, Vijayaragavan R. Acacia catechu ethanolic seed extract triggers apoptosis of SCC-25 cells [Internet]. Vol. 13, Pharmacognosy Magazine. 2017. p. 405. Available from: http://dx.doi.org/10.4103/pm.pm_45 8_16

[45] Perumalsamy H, Sankarapandian K, Veerappan K, Natarajan S, Kandaswamy N, Thangavelu L, et al. In silico and in vitro analysis of 
coumarin derivative induced anticancer effects by undergoing intrinsic pathway mediated apoptosis in human stomach cancer [Internet]. Vol. 46, Phytomedicine. 2018. p. 119-30. Available from: http://dx.doi.org/10.1016/j.phymed. 2018.04.021

[46] Ezhilarasan D, Sokal E, Najimi M. Hepatic fibrosis: It is time to go with hepatic stellate cell-specific therapeutic targets [Internet]. Vol. 17, Hepatobiliary \& Pancreatic Diseases International. 2018. p. 192-7. Available from: http://dx.doi.org/10.1016/j.hbpd.201 8.04 .003

[47] Gheena S, Ezhilarasan D. Syringic acid triggers reactive oxygen species-mediated cytotoxicity in HepG2 cells [Internet]. Vol. 38, Human \& Experimental Toxicology. 2019. p. 694-702. Available from: http://dx.doi.org/10.1177/09603271 19839173

[48] Ezhilarasan D. Oxidative stress is bane in chronic liver diseases: Clinical and experimental perspective [Internet]. Vol. 19, Arab Journal of Gastroenterology. 2018. p. 56-64. Available from: http://dx.doi.org/10.1016/j.ajg.2018. 03.002

[49] Karthiga P, Rajeshkumar S, Annadurai G. Mechanism of Larvicidal Activity of Antimicrobial Silver Nanoparticles Synthesized Using Garcinia mangostana Bark Extract [Internet]. Vol. 29, Journal of Cluster Science. 2018. p. 123341. Available from: http://dx.doi.org/10.1007/s10876018-1441-z

[50] Rajeshkumar S, Kumar SV, Ramaiah A, Agarwal H, Lakshmi T, Roopan SM. Biosynthesis of zinc oxide nanoparticles usingMangifera indica leaves and evaluation of their antioxidant and cytotoxic properties in lung cancer (A549) cells. Enzyme Microb Technol. 2018 Oct;117:915.

[51] Rajeshkumar S, Agarwal H, Venkat Kumar S, Lakshmi T. Brassica oleracea Mediated Synthesis of Zinc Oxide Nanoparticles and its Antibacterial Activity against Pathogenic Bacteria [Internet]. Vol. 30, Asian Journal of Chemistry. 2018. p. 2711-5. Available from: http://dx.doi.org/10.14233/ajchem.2 018.21562 
[52] Menon S, Ks SD, Santhiya R, Rajeshkumar S, S VK. Selenium nanoparticles: A potent chemotherapeutic agent and an elucidation of its mechanism [Internet]. Vol. 170, Colloids and Surfaces B: Biointerfaces. 2018. p. 280-92. Available from: http://dx.doi.org/10.1016/j.colsurfb. 2018.06.006

[53] Mehta M, Deeksha, Tewari D, Gupta G, Awasthi R, Singh H, et al. Oligonucleotide therapy: An emerging focus area for drug delivery in chronic inflammatory respiratory diseases [Internet]. Vol. 308, Chemico-Biological Interactions. 2019. p. 206-15. Available from: http://dx.doi.org/10.1016/j.cbi.2019. 05.028

[54] Crawley E, Sterne JAC. Association between school absence and physical function in paediatric chronic fatigue syndrome/myalgic encephalopathy [Internet]. Vol. 94, Archives of Disease in Childhood. 2009. p. 752-6. Available from: http://dx.doi.org/10.1136/adc.2008.1 43537

[55] Price JR, Mitchell E, Tidy E, Hunot
V. Cognitive behaviour therapy for chronic fatigue syndrome in adults. Cochrane Database Syst Rev. 2008 Jul 16;(3):CD001027.

[56] Nijhof SL, Bleijenberg G, Uiterwaal CSPM, Kimpen JLL, van de Putte EM. Effectiveness of internet-based cognitive behavioural treatment for adolescents with chronic fatigue syndrome (FITNET): a randomised controlled trial. Lancet. 2012 Apr 14;379(9824):1412-8.

[57] Chalder T, Deary V, Husain K, Walwyn R. Family-focused cognitive behaviour therapy versus psycho-education for chronic fatigue syndrome in 11- to 18-year-olds: a randomized controlled treatment trial [Internet]. Vol. 40, Psychological Medicine. 2010. p. 1269-79. Available from: http://dx.doi.org/10.1017/s00332917 0999153x

[58] Baker R, Shaw EJ. Diagnosis and management of chronic fatigue syndrome or myalgic encephalomyelitis (or encephalopathy): summary of NICE guidance [Internet]. Vol. 335, BMJ. 2007. p. 446-8. Available from: http://dx.doi.org/10.1136/bmj.39302 
$.509005 . \mathrm{ae}$

[59] White PD, Sharpe MC, Chalder T, DeCesare JC, Walwyn R, PACE trial group. Protocol for the PACE trial: a randomised controlled trial of adaptive pacing, cognitive behaviour therapy, and graded exercise, as supplements to standardised specialist medical care versus standardised specialist medical care alone for patients with the chronic fatigue

syndrome/myalgic

encephalomyelitis

or encephalopathy. BMC Neurol. 2007 Mar 8;7:6.

[60] Moss-Morris R, Deary V, Castell B. Neurological Rehabilitation: Chapter 25. Chronic fatigue syndrome. Elsevier Inc. Chapters; 2013. 680 p. 